\title{
INCREASED FREQUENCY OF HLA B17 ANTIGEN IN GIRLS WITH TURNER SYNDROME AND THEIR FATHERS
}

\author{
C. DACOU-VOUTETAKIS*, N. GEORGOPOUlOS, H. PAPPA, K. VLACHOS, K. TARASSI, D. \\ CHRYSSOVERGI, CHR. PAPASTERIADES \\ Endocrine Unit, First Paediatric Department, Athens University, Department of Immunology and \\ Histocompatibility, Evangelismos Hospital, Athens, Greece.
}

\author{
SUMMARY
}

HLA-A, -B and -DR antigen distribution was studied in 49 girls with Turner Syndrome (TS), in 43 of their parents, as well as in 433 controls. No increased frequency of DR3, DR4 was found in our group. However, an increased frequency of HLA B 17 antigen was disclosed $\left(18.3 \%\right.$ in TS versus $6.4 \%$ in the controls, $p<0.001$ and $\left.p_{c<} 0.01\right)$. Furthermore, the HLA B 17 antigen was of paternal origin in $77.7 \%$ of the cases. The interpretation of the present findings is quite difficult. Most likely, the findings are related to the chromosomal abnormality rather than to autoimmunity. It is quite possible that genes within the region of class I genes create unfavorable circumstances leading to the loss of the sex chromosome or, alternatively, genes in this region confer protection and prevent miscarriage of the affected fetus.

KEY WORDS: Turner Syndrome HLA antigens

\section{INTRODUCTION}

Glucose intolerance and autoimmune phenomena are more frequently encountered in girls with Turner Syndrome (TS) than in the general population (Cassidy et al., 1978; Grunciro de Papendik et al., 1987; Larizza et al., 1989). A study was designed to investigate the diabetic tendency in girls with Turner Syndrome by determining, among other parameters, the HLA-A, -B and -DR antigens. An interesting, unexpected finding, of increased frequency of HLA B17 antigen emerged which is reported here-in.*

\section{MATERIALS AND METHODS}

HLA-A, -B and -DR antigen distribution was studied in 49 girls with Turner Syndrome and in 43 of their parents. 433 healthy, unrelated individuals served as controls. All subjects tested were of Greek origin. Almost $90 \%$ of the cases of TS were examined for shortness of stature. A few girls presented with lyphedema in the neonatal period and one presented with hypertension. Their chromosome constitution is depicted in Table 1 (A). The typing of HLA-A, -B and -DR antigens was

*Correspondence to: C. Dacou-Voutetakis, Athens University, First Dept. of Paediatrics, St. Sophia Children's Hosp., Goudi, 11527 Athens, Greece. Fax: (01) 7795538. 
Table 1: Chromosome Constitution of studied patients.

\begin{tabular}{c|c}
\hline A. In the total group, tested & B. In girls wih TS and B17 antigen \\
\hline 45X:22 (45\%) & $45 X: 6(60 \%)$ \\
45X/46XX:8 $(16.3 \%)$ & $45 X / 46 X X: 4(40 \%)$ \\
46XiXq:7 (14.2\%) & \\
Miscel: $12(24.5 \%)$ & \\
\hline
\end{tabular}

performed by the classical two-step microlymphocytotoxicity test. The isolation of the cells was carried out by monoclonal antibodies specific for CD8 antigen (for HLA-A, -B typing) or DR $\beta$ chain monomorphic epitope (for HLA-DR typing), using immunomagnetic isolation techniques. The control subjects were blood donors and hospital personnel. The results were analysed using the chi square test.

\section{RESULTS}

The HLA-A, -B antigens, which were tested, their $\%$ frequency in TS girls and controls, as well as the difference in antigen distribution (indicated by $\mathrm{p}$ value) are shown in Table 2. The frequency of HLA-DR3 and -DR4 antigen did not differ in girls with TS, in comparison to the controls.

The HLA-B 17 antigen was found in 9 girls with TS $(18,3 \%)$ and in 28 of the controls $(6.4 \%)$. This difference was statistically significant $\left(\mathrm{p}<0.001, \mathrm{p}_{\mathrm{c}}<0.01\right)$. The frequency of the B 17 antigen in the fathers tested was $16.3 \%(\mathrm{p}<0.01)$, while in the mothers it was $4.5 \%$.

Of the 9 girls, who possessed HLA B 17 antigen, 7 inherited the antigen from their father, one from the mother, while in one B17 antigen was inherited from both parents. Thus, the HLA B 17 antigen was of paternal origin in $77.7 \%$ of the girls. The distribution of the HLA-B17 antigen, according to chromosome constitution, is depicted in table 1 (B) and it shows that all girls with this antigen had, either, $45 \mathrm{X}$ or 45X/46XX mosaic.

\section{DISCUSSION}

No increased frequency of HLA-DR3 and -DR4 antigens was noticed in our group, another indication that the pathogenesis of glucose intolerance in girls with TS is different from that of type I diabetes mellitus. It is quite interesting, however, that the HLA-B 17 antigen was more frequently observed in girls with TS (18.3\% versus $6.4 \%$ in the controls). The number of subjects studied does not allow an evaluation of the effect of the type of chromosomal aberration (Table 1B). It may be pertinent, however, that 6 of the 10 cases were $45 \mathrm{X}$ and the remaining were $45 \mathrm{X} / 46 \mathrm{XX}$ mosaic. Most interesting was the observation that in $77.7 \%$ of the cases the HLA B 17 antigen was of paternal origin. 
Table 2: Distribution (\%) of HLA-A, -B antigens tested in subjects with Turner Syndrome and in controls.

\begin{tabular}{|c|c|c|c|}
\hline & $\begin{array}{l}\text { Controls } \\
(n=433)\end{array}$ & $\begin{array}{l}\text { TS girls } \\
(n=49)\end{array}$ & \\
\hline HLA & $\%$ & $\%$ & $\mathrm{P}$ \\
\hline A-1 & 24 & 14.2 & N.S. \\
\hline 2 & 53.1 & 50 & N.S. \\
\hline 3 & 13.6 & 11.9 & N.S. \\
\hline 9 & 33 & 30.9 & N.S. \\
\hline 10 & 11.5 & 9.5 & N.S. \\
\hline 11 & 10.6 & 9.5 & N.S. \\
\hline 19 & 22.1 & 30.9 & N.S. \\
\hline 28 & 5.7 & 14.2 & N.S. \\
\hline B-5 & 28.8 & 26.1 & N.S. \\
\hline 7 & 8.1 & 4.7 & N.S. \\
\hline 8 & 9.7 & 9.5 & N.S. \\
\hline 12 & 17.5 & 14.2 & N.S. \\
\hline 13 & 3.2 & 4.7 & N.S. \\
\hline 14 & 5.3 & 2.3 & N.S. \\
\hline 15 & 6.4 & 4.7 & N.S. \\
\hline 16 & 8 & 7.1 & N.S. \\
\hline 17 & 6.4 & 18.3 & $\mathrm{p}<0.001^{*}$ \\
\hline 18 & 19.6 & 21 & N.S. \\
\hline 21 & 8.1 & 12 & N.S. \\
\hline 22 & 6.2 & 2.3 & N.S. \\
\hline 27 & 5.7 & 4.7 & N.S. \\
\hline 35 & 31.6 & 35.7 & N.S. \\
\hline 37 & 3.4 & 0 & N.S. \\
\hline 40 & 9 & 4.7 & N.S. \\
\hline
\end{tabular}

$* \mathrm{p}<0.01$ after correction for the number of antigens tested. 
Cassidy et al. (1978) in studying 23 girls with TS found no increased frequency in any of the HLA antigens tested. Their population group however was rather small. It should also be mentioned that in a study of 46 girls with TS from Northern Italy ((Larizza et al., 1989) aiming at the evaluation of their autoimmune tendency, a high frequency of HLA-B38 and -A31 antigen was observed. However, the difference from the controls, in this sample, was not significant, after correction for the number of antigens tested. Thus far, the HLA-B17 antigen has not been associated with any autoimmune disorder and our findings should not be related to the autoimmune phenomena known to occur more frequently in TS. Hence, another relation of the finding, if any, to the syndrome should be sought. On the other hand it has been shown that the lost sex chromosome in TS is paternal in about $80 \%$ of the cases (Hassold et al., 1991; Loughlin et al., 1991; Cockwell et al., 1991) and it may not be irrelevant that the HLA-B 17 antigen, in our study of girls with TS, was paternal in $77.7 \%$ of the cases. Furthermore, southern blot analysis of human genomic DNA with HLA Class I cDNA probes (Trowsdale et al., 1991) supports the idea that the HLA-class I gene family includes genes apart from those encoding HLA-A, -B and -C antigens.

Based on the above, admittedly limited, data, one would like to speculate that gene(s) within the HLA-class I region could create unfavorable circumstances leading to the loss of the sex chromosome. Alternatively, gene(s) in these loci perhaps offer protection and prevent miscarriage, which is known to be a very frequent event in $\mathrm{XO}$ embryos.

It is obvious that the precise interpretation and significance of the increased frequency of HLA-B17 antigen in girls with TS, inherited from their fathers, must await further studies.

\section{REFERENCES}

Cassidy, S.B., Niblach, G.D., Lorber, C.A., Mann, J.M., Engel, E. (1978). HLA frequencies, diabetes mellitus and autoimmunity in Turner's patients and their relatives. Ann. Genet., 21 (4), 203-208.

Cockwell, A., MacKenzie, M., Youings, S., Jacobs, P. (1991). A cytogenetic and molecular study of a series of $45 \mathrm{X}$ fetuses and their parents. J. Med. Genet., 28, 151-155.

Grunciro de Papendik, L., Forcansky, S., Coco, R., Rivarola, M.A., Berganda C. (1987). High incidence of thyroid disturbances in 49 children with Turner Syndrome. J. Pediatr., 111, $258-261$.

Hassold, T., Benham, F., Leppert, M. (1988). Cytogenetic and molecular analysis of sexchromosome monosomy. Am. J. Hum. Genet, 42, 534-41.

Larizza, D., Martinetti Bianchi, M., Lorini, R., Maghnie, M, Dugoujon, J.M., Cuccia Belvedere, M., Severi, F. (1989). Autoimmunity, HLA, Gm and Km polymorphisms in Turner's Syndrome. Autoimmunity, 4, 69-78.

Loughlin, S.A.R., Redha, A., Mclver, J., Boyd, E., Carothers, A., Connor, J.M. (1991). Analysis of the origin of Turner's Syndrome using polymorphic DNA probes. J. Med. Genet., 28, 156-158.

Trowsdale, J., Pagoussis, J., Campbell, R.D. (1991). Map of the human MHC. Immunology today, 12, 443-446.

- Presented in part at the 74th annual meeting of the Amer. Endocr. Soc., San Antonio, Texas, June 24-27, 1992, abs. No. 878. 


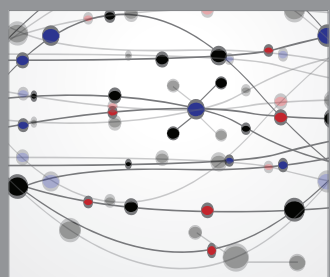

The Scientific World Journal
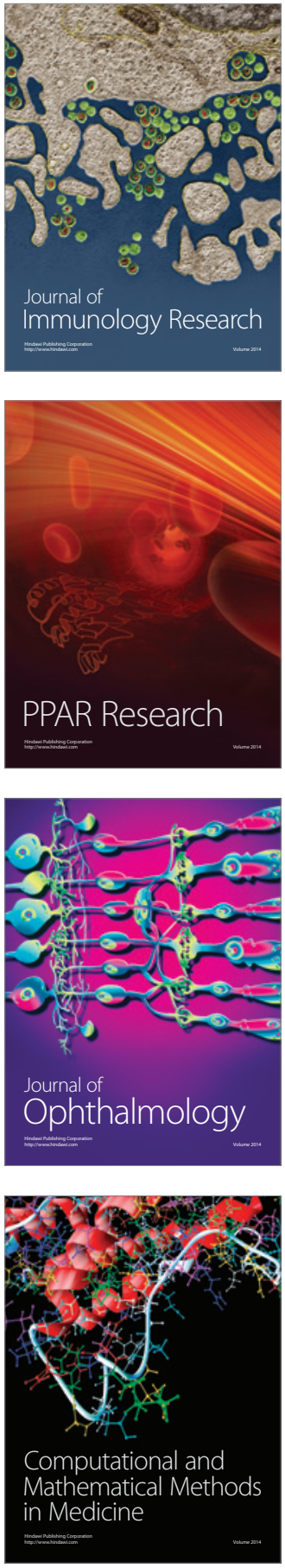

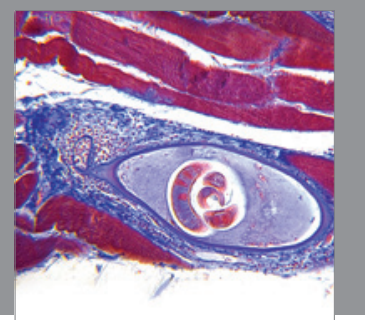

Gastroenterology

Research and Practice
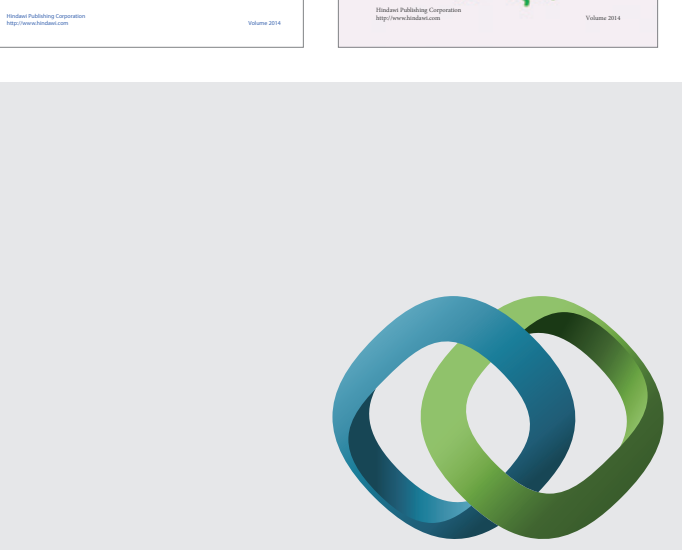

\section{Hindawi}

Submit your manuscripts at

http://www.hindawi.com
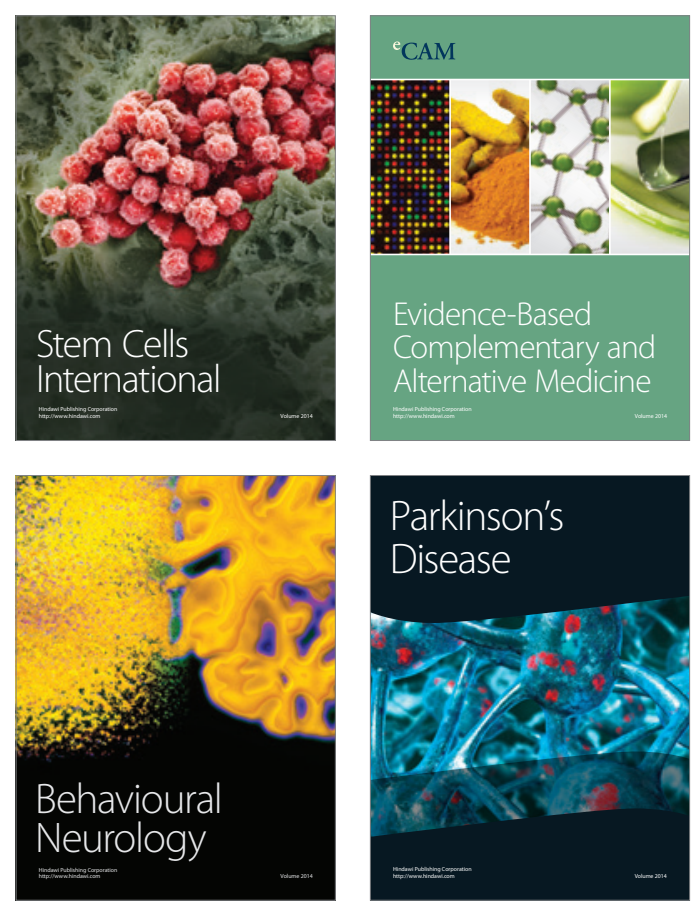

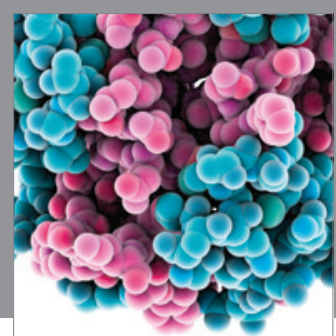

Journal of
Diabetes Research

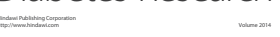

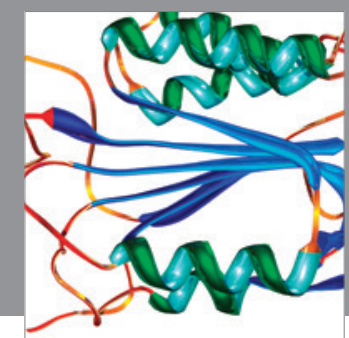

Disease Markers
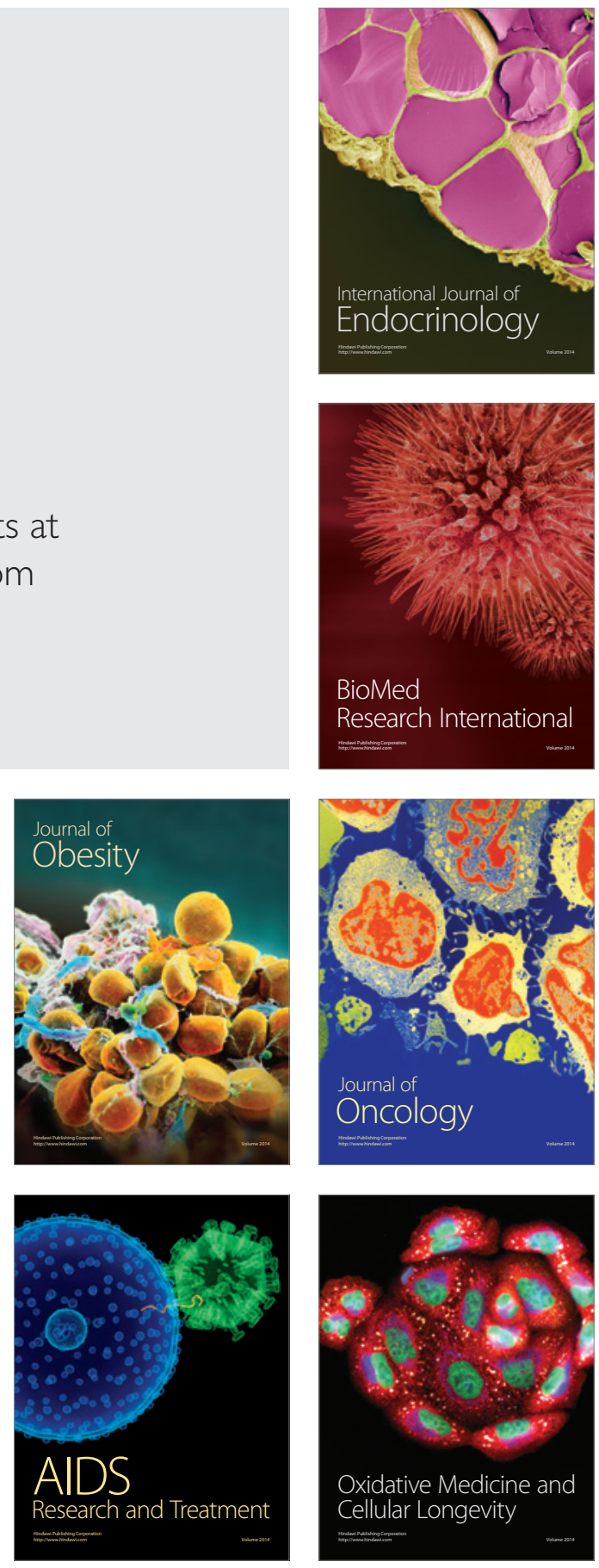